\title{
Cidadania e inserção laboral assistida: a experiência do trabalho formal de adolescentes pobres
}

\author{
Victor Hugo da Silva \\ Prefeitura Municipal de Colatina-ES
}

\begin{abstract}
Resumo
Investiga o cotidiano de adolescentes pobres partindo do relato do processo de entrada no mercado de trabalho. Participaram 15 adolescentes, sexo masculino, estudantes do Ensino Médio, de famílias de baixa renda, com 18 meses de inserção profissional, assistidos por instituição que capacita, insere e acompanha adolescentes no mercado de trabalho formal numa capital brasileira. Os dados foram coletados através de entrevistas semiestruturadas. Os resultados, considerando que a inserção profissional é uma forma de exercício da cidadania, mostram que: a inserção assistida no mercado de trabalho formal não constitui garantia absoluta de proteção aos seus direitos; as redes sociais às quais se vinculam podem ocultar violações de direitos ao se basear em relações de clientelismo; a assimilação de valores sociais do contexto de relações do ambiente laboral pode implicar afastamento do grupo de pares. Entretanto, os adolescentes avaliaram positivamente o acompanhamento fornecido pela instituição.
\end{abstract}

Palavras-chave: inserção laboral assistida; adolescente trabalhador; cidadania; direitos sociais.

\begin{abstract}
Citizenship and assisted labour insertion: poor adolescents experience in the formal work. It investigates the everyday of poor adolescents based on the report of their job market insertion process. 15 male adolescents have participated on the survey, high school students coming from low-income families, with 18 months of professional insertion, assisted by institutions that empower, insert and accompany adolescents in the formal job market in a Brazilian capital. Data were collected through semi-structured interviews.

Considering that professional insertion is a way of citizenship practice, the results show that: assisted insertion in the formal job market is not a total guarantee of protection to their rights; social networks to which they are linked to, can conceal violations of rights when based on relationships of currying favor; the assimilation of social values in the context of relationships in the workplace can result in removal from the Group of peers. However, adolescents have evaluated positively the monitoring provided by the institution.

Keywords: assisted labour insertion; adolescent worker; citizenship; social rights
\end{abstract}

A entrada de adolescentes no mercado de trabalho formal vem cada vez mais se configurando como um campo de promoção de direitos sociais básicos e acesso à cidadania. Contudo, diversos autores apontam que esse trabalho deve vir acompanhado de uma dimensão educativa, além da simplesmente produtiva. Aliadas ao discurso da promoção do emprego formal como forma de superação da marginalidade estão diversas instituições que se propõem a tarefa de garantir a preservação de direitos, inclusive trabalhistas, a essa fatia da população economicamente ativa, considerando sua condição especial de adolescente como sujeito em desenvolvimento.

Nesse contexto, este trabalho apresenta os resultados de uma pesquisa cujo objetivo foi investigar o cotidiano de adolescentes pobres partindo do seu relato do processo de entrada no mercado de trabalho formal. Até que ponto a inserção assistida de adolescentes no mercado de trabalho formal constitui garantia de proteção aos seus direitos? Que possibilidades se abrem ao adolescente a partir de sua participação nas redes de relações sociais às quais passam a integrar no ambiente de trabalho formal? Qual o impacto dos valores sociais assimilados no contexto de relações do ambiente laboral? Como os próprios adolescentes avaliam essa inserção? Foi pensando nessas perguntas que nos declinamos diante do que os próprios adolescentes têm a dizer.

Assim, consideramos que o fenômeno do trabalho exercido por crianças e adolescentes não é novo, no entanto, torna-se problema a partir das diversas transformações históricas e sociais que marcam o advento das sociedades modernas e do modo de produção capitalista, fazendo emergir uma maneira diferente de lidar com a "infância". Ariès (1981) demonstra que a criança, durante parte da Idade Média, era considerada um ser relativamente indiferente, cuja morte era considerada um "desperdício necessário". Nos séculos XIV e XV configurase certa tendência de diferenciar o mundo dos adultos e das crianças, consideradas pitorescas e engraçadinhas, anunciando 
o surgimento do sentimento moderno de infância. "Foi somente no século XVIII, com o surgimento do malthusianismo e a extensão das práticas contraceptivas, que a idéia de desperdício necessário desapareceu" (Ariés, 1981, p. 58). A criança passou a ser depositária de uma série de práticas especiais de cuidado, cujo fim era maximizar suas chances de sobrevivência - a morte não é mais necessária, mas decorrência da falta das condições de cuidado que permitem esse ganho de sobrevida.

Nos séculos XVIII e XIX assiste-se o surgimento da noção de população que, para Foucault (2000), é um problema político, científico e biológico, envolvendo fenômenos que pediam diversas formas de regulação. Além do estabelecimento de mecanismos reguladores de fenômenos amplos e relativamente aleatórios (natalidade, mortalidade, endemias, epidemias, taxas de emprego, etc.), essa noção implica e fundamenta o exercício do poder político nos limites de um determinado território geográfico caracterizado pelo que Bauman (1999) chama de "nação-estado". Essa tinha por tarefa "produzir a ordem", requerendo "imensos e contínuos esforços para depurar, transferir e condensar o poder social", exigindo "recursos consideráveis que somente o Estado, na forma de um aparelho burocrático hierárquico, é capaz de reunir, concentrar e usar" (p. 69). A soberania legislativa e executiva, apoiada no tripé das "soberanias militar, econômica e cultural", implica que todos os "recursos outrora utilizados pelos focos difusos de poder social" passam a tornar-se "necessários para sustentar a instituição e a manutenção da ordem administrativa pelo Estado" (Bauman, 1999, p. 69). Esse processo eclode na emergência de novos saberes, reordena o espaço num âmbito planetário, regulamenta as variáveis socioeconômicas que caracterizam uma população para fortalecê-la, mantendo o ritmo de produção de riquezas. Surge, assim, o problema da infância considerada risco eminente à ordem social e econômica do Estado - aquela que não se enquadra nos moldes de produção de infância instaurados pelas diversas disciplinas que se debruçam sobre a criança e o adolescente como objeto de intervenção e investigação.

Desde a Idade Média, um setor crescente da população vinha se desenvolvendo e antecipando a "grande massa que seria despojada de seus meios de vida no processo da Revolução Industrial" marginalizada "das relações dominantes de produção: mendigos, vagabundos, píncaros, órfãos, etc.” (Enguita, 1989, p. 108). Considera o autor que "a inquietude pelas crianças órfãs e os filhos de pobres não era nova, havendo nascido da preocupação pela ordem pública e pelo desperdício que, para a nação em geral, representavam seus braços inativos" (p. 108). Sua simples existência, sem nenhuma espécie de controle exceto as passagens regulares por órgãos de polícia e da justiça, era interpretada como risco eminente de desmoronamento da ordem social estabelecida. Tornado o trabalho um imperativo moral, os que vivem no ócio passaram a ser considerados vicioso", portadores de delinquência, libertinos, maus pais e vadios, particularmente se pobres. Como "perigo social", "deveria ser erradicado; daí a necessidade de medidas coercitivas também para essa parcela da população, considerada de criminosos em potencial" (Coimbra \& Nascimento, 2003, p. 24). O processo de industrialização, durante o século XVIII, "converteu definitivamente as crianças na guloseima mais cobiçada pelos industriais: diretamente, como mão de obra barata, e indiretamente, como futura mão de obra necessitada de disciplina"; uma vez que refletia o "desejo de ver universalmente internadas as crianças pobres, e 'escolarizadas', o que fundamentalmente significava submetidas a muitas horas de trabalho e alguma instrução" (Enguita, 1989, p. 109).

Para Minayo-Gomez e Meirelles (1997), as justificativas ideológicas utilizadas para o uso da força de trabalho de crianças e adolescentes pobres são, hoje, semelhantes à concepção do início da industrialização. Legitimam socialmente sua exploração nas fábricas, em condições de desigualdade em relação às do adulto, como forma de "proteção do crime e da marginalidade". Tornado o espaço da rua marginal por excelência, tido como desorganizado e desregulado, o espaço fabril, seu oposto, passou a funcionar como remédio privilegiado. No rastro dessas transformações, a adolescência foi estabelecida como um período de transição para a vida adulta, marcado principalmente pela escolarização, nas classes mais abastadas. Esse conceito se justificou na prática pela necessidade de compreensão e intervenção em toda uma gama de fenômenos físicos, cognitivos e emocionais, que implicam também processos de diferenciação social do indivíduo como adolescente. "A tendência de se limitar o adolescente a 'um indivíduo em período de transição' tem favorecido o esquecimento de suas necessidades e a falta de respeito de seus direitos enquanto cidadão" (Minayo-Gomez e Meirelles, 1997, p. 136).

O Brasil se manteve histórica e ideologicamente em posição periférica em relação aos centros do desenvolvimento econômico mundial, enquanto países europeus e os Estados Unidos definiam o que é modernidade ou atraso e mantinham a hegemonia global dos modelos econômicos em diversos momentos. Na transição da sociedade agroexportadora para a urbano-industrial a partir de 1930, a modernidade era expressa por um Estado forte e intervencionista. Nas décadas de 1950 e 1960, o ideário nacionalista reforçou o modelo estatocêntrico, contrastando com 1980, quando "Estatismo, nacionalismo e intervencionismo (...) seriam estigmatizados [como ultrapassados] e o pólo moderno passaria a ser representado pela trilogia mercado, livre iniciativa e internacionalismo" (Diniz, 2000, pp. 7-8).

O surgimento de uma indústria de base cafeeira e outra ligada a necessidades básicas do mercado interno condicionou a importação da Europa de trabalhadores especializados e a progressiva segregação dessa franja da população para as periferias. O avanço da urbanização inchou as cidades, “que não desenvolveram suficientemente sua capacidade produtiva para atender com emprego à população imigrante, que acaba relegada ao terciário informal" (Maricato, 2000, p. 24), contribuindo para a "desarticulação da rede urbana". A República Velha assistiu uma crescente adoção da rua como espaço de trabalho da população marginalizada.

Segundo Costa (1990), em 1927 instaura-se o Código de Menores, por meio do qual se transforma em "menor", meninos e meninas em situação de marginalidade, sendo, então, enquadrados nos diversos itens da chamada "situação irregular". Sob esse rótulo, passam a compor a clientela dos programas abertos ou fechados de atendimento executados por órgãos da política menorista do Estado brasileiro. Caracterizado esse campo de intervenção, entre 1930 e 1943 o atendimento 
aos menores e outras iniciativas de proteção social da infância consolidou-se, na área do trabalho, na normatização de ações preventivas de saúde, na assistência social e na obrigatoriedade do ensino fundamental (Mendonça, 2002). Costa (1990) aponta que essa definição de "menor" passa a dar sustentação, na prática, a um enfoque correcional-repressivo, que, apoiado na noção de "periculosidade", funcionava com o pressuposto de que constituía uma "ameaça social", concepção acirrada na vigência do Estado Novo.

No período da ditadura Pós-1964, as instituições de internamento já são percebidas pelas elites como verdadeiras "escolas do crime", entendendo ser preciso minimizar o risco social crescente. Assim, o Estado valeu-se de certa engenharia social a fim de solucionar uma gama de problemas vivenciados pelas classes menos favorecidas. O tratamento dispensado aos "menores" sofre modificações, segundo nova racionalidade instituída pela Política Nacional de Bem-Estar do Menor definida na Lei $N^{\circ} 4.513 / 64$, vigorando até 1988 (Mendonça, 2002). O enfoque correcional-repressivo cede espaço ao assistencialista, cujas estratégias de atendimento se apoiam na noção de privação. $\mathrm{O}$ adolescente de classe média vira padrão de normalidade; o "menor" marginalizado é considerado "carente bio-psico-sóciocultural, ou seja, um feixe de carências" (Costa, 1990, p. 82) e "o atendimento pautou-se pela tentativa de restituir à criança e ao jovem tudo o que lhe havia sido sonegado no âmbito das relações sociais" (Costa, 1990, p. 83). Amparado no ideário do Welfare State, que implicava a tentativa de prover o acesso a bens e serviços relacionados com a garantia de um patamar mínimo de bem-estar social, via promoção de direitos sociais (Magalhães, 2002), o Estado visa à satisfação das necessidades básicas dos cidadãos, num modelo de atenção que tenta equiparar o Brasil a países capitalistas considerados desenvolvidos.

A ideia de prevenção determinava uma ação estatal diferencial em função da exposição da população a diferentes taxas de risco, ora impedindo o aumento da degradação pessoal e social do assistido, ora ampliando o acesso aos direitos básicos. Imprime-se aos programas assistenciais um caráter compensatório, tanto das carências de seus destinatários, quanto da não universalidade das políticas sociais básicas. Na prática, efetivou-se um controle minucioso da vida social e política, de caráter fortemente intervencionista, delegando um papel meramente passivo à massa da população. As ações, planejadas por uma elite tecnocrática, excluía a sociedade da deliberação dessas políticas (Diniz, 2000; Ferreira, 2001). Apoiado numa base estrutural e historicamente desigual, "o welfare state não passou de direitos para alguns” (Maricato, 2000, p. 27), não vigorando um Estado de Bem-Estar Social strictu sensu no Brasil.

Assim, diversos autores apontam um agravamento dos problemas sociais vividos por crianças e adolescentes no período ditatorial. Destacam-se: a permanência, mais sutilmente elaborada, do enfoque correcional-repressivo (Costa, 1990) e o descompromisso político com a transformação da realidade social refletido no pragmatismo intervencionista, e a morosidade das reflexões acadêmicas (Ferreira, 2001). Mais recentemente, a partir da década de 1980, com a abertura do regime político e mudanças que culminaram na adoção de uma cartilha econômica neoliberal, ditada internacionalmente, o Estado reproduziu as alternativas práticas de trabalho social de movimentos civis organizados, sem relação com seus valores de base. Entram em cena: a redução neoliberal progressiva dos investimentos em direitos sociais básicos delegando à educação o mero enquadramento do indivíduo à sociedade empresarial e às tecnologias (Estêvão, 2001); a redução das taxas de emprego com a nova política econômica (Shiroma \& Campos, 1997; Campos \& Francischini, 2003); as mudanças nas relações de trabalho decorrentes da globalização da economia (Sarmento, 2002); e ainda, a vigência do Estado mínimo (Diniz, 2000).

A flexibilização das relações de trabalho daí resultantes significou a indevida utilização, em larga escala, da força de trabalho infantil e adolescente como componente estrutural da economia brasileira, principalmente por seu caráter de mão de obra dócil, barata e desorganizada sindicalmente. São múltiplas as formas como se dá essa inserção precoce no mercado de trabalho, bem como as tarefas a seu encargo. Desfavoráveis ao adolescente estão: "o baixo nível de escolaridade, a ausência de políticas de capacitação para o trabalho e uma fluidez completa que lhes imprime a condição de trabalhador generalista, pronto para qualquer tarefa" (Ferreira, 2001, p. 218). Isso justifica sua utilização como "pau para toda obra", em marcante contradição entre as "razões alegadas para sua contratação" e "as funções que exerce". A condição de sub-cidadão representa uma triagem inicial para a única porta que ainda parece aberta: um submercado de trabalho explorador, irregular e sub-remunerado. Por essa via, adolescentes participam da estratégia de sobrevivência de suas famílias, muitas vezes sendo responsáveis sozinhos por elas (Costa, 1990; Fischer, Oliveira, Teixeira, Teixeira \& Amaral, 2003; Minayo-Gomez \& Meirelles, 1997; Oliveira \& Robazzi, 2001). O custo social acaba sendo a renúncia a um grau de escolaridade maior.

Pensando a participação ativa do adolescente no processo de transformação de sua realidade, Minayo-Gomez e Meirelles (1997) reforçam a possibilidade de outro enfoque, distinto da concepção de adolescência como "fase de transição", destacando a valorização social de seu potencial de contribuição, na medida em que seus pensamentos, desejos e críticas sejam ouvidos. Importa concebê-lo não mais como "feixe de carências", donde caberia perguntar "o que ele é, o que ele sabe, o que ele traz e do que ele é capaz” (Costa, 1990, p. 83). No plano das relações sociais cotidianas é que se enfrentam as condições adversas que reincluem o cidadão nos quadros do desemprego, da subcidadania, da fome, da desqualificação profissional, além do desinvestimento em si como pessoa.

Institucionalmente essas ideias se traduziram no conceito de protagonismo juvenil, debatido a partir do surgimento de movimentos culturais, nos quais o jovem tem figurado como principal ator do processo (Iulianelli, 2003). É o caso dos movimentos nacionais de meninos e meninas de rua, a partir de 1980, e do rap, hip-hop e funk a partir de 1990. Porém, Iulianelli (2003) considera o conceito um campo semântico em disputa, muitas vezes tratando-se de um discurso mais utilizado pelos educadores e trabalhadores sociais que pelos próprios atores juvenis. No dito protagonismo haveria "estratégias do neoliberalismo de reestruturação da capacidade de decisão 
dos agentes do sistema educativo, facilitadoras da retirada do protagonismo do Estado das Políticas Sociais que garantem os serviços essenciais de educação" (Rossi, 2001, p. 94).

Parte dessa controvérsia se deve ao parentesco com o conceito de empowerment (empoderamento), que Iulianelli (2003) define como a capacidade de participação, luta por direitos e assunção de responsabilidades, realização e integração social. Sugere que, no caso dos jovens, empoderar significa conferirlhes poder como indivíduos, membros de organizações juvenis, comunidades ou corpos nacionais ou internacionais. Para os jovens e educadores sociais envolvidos, o foco se desloca para “o próprio processo formador que se dá por meio da ação juvenil: a questão central é a construção da cidadania e da participação" (Iulianelli, 2003, p. 71). Entretanto, os discursos de valorização da gestão de recursos humanos, por sua vez, escondem "práticas formativas restritivas e tayloristicamente especializadas, reforçando uma cultura integradora e o modo como a organização manipula o poder" fazendo "aumentar, sob a capa do empowerment individual, o empowerment sobre o indivíduo, impedindo simultaneamente alterações políticas mais radicais (Estêvão, 2001, p. 188).

O estímulo à atividade laboral como mediadora da solução de problemas pessoais e sociais, institucionalizada na criação de programas educativos, tem se constituído em instrumento de legitimação para a manutenção e reprodução social da pobreza e da estrutura ocupacional (Minayo-Gomez \& Meirelles, 1997). Resulta numa atuação meramente profissionalizante, sob a justificativa de promover políticas sociais redistributivas. Em contrapartida, Oliveira, Fischer, Amaral, Teixeira e Sá (2005) destacam a positividade do trabalho ao referenciar autores para quem as motivações dos adolescentes, uma vez satisfeitas no exercício do trabalho, podem proporcionar um sentimento de independência, de autovalorização e respeito, contribuindo para a formação de uma autoimagem positiva. Assim, o trabalho adolescente deveria ser acompanhado de um princípio educativo (Shiroma \& Campos, 1997). E a educação, que consolida o direito ao trabalho, não deve vê-lo como estorvo ao processo educativo (Oliveira \& Robazzi, 2001).

Com a entrada em vigor do Estatuto da Criança e do Adolescente (ECRIAD), Lei nº 8.069/1990, o trabalho não deixa de poder ser exercido por adolescentes. Os Artigos 60 a 69 elevam o trabalho à condição de direito. Assim, a profissionalização deve ser acompanhada de medidas de proteção que respeitem a condição peculiar de pessoa em desenvolvimento. São elas: acesso a capacitação quando o trabalho for exercido com propósitos educativos, seja em ONGs ou instituições governamentais, respeitando a Lei de Diretrizes e Bases da Educação; não-exposição a ambientes prejudiciais a sua formação integral; garantia de acesso ao ensino regular; prevalência do aspecto educativo sobre o produtivo; proteção aos direitos trabalhistas e previdenciários; dentre outros (Lei ${ }^{\circ}$ 8.069, de 13 de julho de 1990). Contudo, a legislação contém brechas que abrem concessões à exploração de adolescentes como mão de obra barata, particularmente no que tange à forma como o "trabalho educativo" é permitido (Costa, 1990). O ECRIAD define como criança a pessoa até 12 anos incompletos, e adolescente a pessoa entre 12 e 18 anos. Contudo, esse limite varia histórica e socialmente.

Para Piccinini (2004), a reestruturação produtiva reduziu o quadro de pessoal nas grandes empresas, mantendo os trabalhadores mais qualificados. Em compensação, o mercado de trabalho tornou-se precário, aumentando o desemprego industrial e, na pequena e média empresa, o emprego legalmente desprotegido. O trabalhador voltou-se para sua empregabilidade, num contexto em que se valorizam cada vez mais os equipamentos que poupam investimentos em mão de obra. As novas tecnologias introduzidas na indústria fazem vigorar também no setor de serviços, normas de rotinização, fragmentação e desqualificação, transformando as características pessoais dos empregados (aparência, idade, educação, gênero e raça) e sua adequação ao trabalho em potencial produtivo, de forma que tais traços e competências individuais são a condição mesma da empregabilidade (Sorj, 2000). Assim, com a forte estratificação do mercado, minorias, mulheres e jovens com baixa escolaridade ocupam os níveis inferiores de emprego, em tempo parcial ou temporário, reproduzindo sua baixa oportunidade de carreira e mobilidade. Compõe-se um "currículo oculto" de competências intangíveis, que, ao contrário das habilidades técnicas prévias necessárias ao exercício funcional no antigo paradigma do "posto de trabalho", envolvem um componente de saber produzido no contato direto com o mundo, não podendo se transferir mesmo envolvendo situações sociais (Shiroma \& Campos, 1997). Resulta desse processo a culpabilização do trabalhador por sua não contratação ou sua demissão (Estêvão, 2001).

Oliveira, Sá, Fischer, Martins e Teixeira (2001) apontam que o distanciamento e a falta de reflexão das condições vividas no cotidiano por adolescentes trabalhadores podem contribuir para reforçar situações de exploração, exclusão e desqualificação social, de agravos físicos e psicossociais, além de outros processos de vitimização a que podem estar submetidos. Sarriera, Silva, Kabbas e Lopes (2001), a partir da experiência de orientação de adolescentes na busca de emprego, perceberam que seus projetos profissionais tanto não eram inteiramente clarificados, quanto revelavam altas expectativas de futuro, baseadas em escolhas calcadas na fantasia. Assim, pesquisar o cotidiano do adolescente trabalhador, sua experiência concreta e relações sociais aí protagonizadas, possibilita repensar e reorientar práticas sociais relacionadas ao resgate da cidadania em situações de vulnerabilidades múltiplas. Isso a exemplo da pesquisa realizada por Ramos (2002) junto a adolescentes carentes residentes na região metropolitana de Vitória-ES, vinculados ao Programa de Inserção Profissional do Centro Salesiano do Menor (CESAM), que deu destaque, além do trabalho, a variáveis como vida escolar, vida familiar, condições de moradia, relações com amigos e com a comunidade.

\section{Método}

Foram entrevistados 15 adolescentes trabalhadores, com um ano e seis meses de trabalho formal, de carteira assinada, do sexo masculino, com 17 anos, moradores de bairros de periferia da capital de um estado brasileiro, de baixa renda, estudantes do Ensino Médio. Todos vinculados a uma instituição que 
promove a inserção de adolescentes no mercado de trabalho. Em decorrência desse vínculo institucional, os adolescentes tinham sido capacitados. Foram também acompanhados por uma equipe multiprofissional durante todo o período em que se encontravam vinculados à instituição. O Programa de Inserção Profissional mantido pela instituição encaminha adolescentes para empresas públicas e privadas, de pequeno, médio e grande porte; sendo seu objetivo proporcionar uma experiência de trabalho educativo para adolescentes de baixa renda. O Programa é responsável por todos os direitos legais trabalhistas. As empresas conveniadas, beneficiadas pelo trabalho do adolescente, repassam ao final do mês o valor/curso da inserção do jovem trabalhador.

A instituição pauta suas ações por um modelo de resgate, promoção e construção da cidadania, ancorada na noção de protagonismo juvenil. Para isso o Programa prevê os adolescentes passarem pelas seguintes etapas:

Seleção. Entrevista com a assistente social ou psicóloga, verificando sua realidade socioeconômica e sua documentação de acordo com os critérios estabelecidos; provas de Português, Matemática e Redação e, se aprovado, visita domiciliar.

Capacitação. Curso de preparação para o trabalho de 120 horas, divididas em 4 horas diárias, sendo desenvolvidos temas de interesse para a formação humana do adolescente; aulas sobre o ambiente e a rotina de trabalho (legislação do trabalho, ética e relacionamento no ambiente de trabalho, atendimento ao público, dentre outros), seguidos de uma avaliação que verifica a aptidão para ingressar no mercado de trabalho.

Inserção no mercado de trabalho. Aguarda uma vaga compatível com seu horário de estudo e maior acessibilidade quanto ao local de moradia. Com a vaga, sua carteira de trabalho é assinada, recebe uniforme, vale-transporte, um salário mínimo, e, dependendo da empresa, recebe vale-refeição. Permanece no trabalho até completar 18 anos, quando é desligado do programa e recebe os benefícios legais.

Acompanhamento socioeducativo. Visitas ao local de trabalho por assistente social e psicóloga; encontros entre adolescentes para discussão de temas relativos ao cotidiano de trabalho; encontros formativos (com atividades de lazer, cultura, esportes e lanche) e atendimentos dirigidos tanto ao adolescente quanto a sua família.

A coleta de dados foi realizada na forma de entrevista, seguindo um roteiro mínimo de perguntas/estímulos imanentes à vivência dos adolescentes, contemplando fatores tais como: principais mudanças ocorridas depois de ingressar em trabalho formal; o que não mudou; expectativas que tinha no início do trabalho; processo de adaptação às atividades do trabalho; avaliação que faz do trabalho (em todos os aspectos: organização, ambiente, etc.); opinião dos colegas de trabalho em relação ao adolescente e aos serviços executados; motivações atuais para continuar na atividade; situações marcantes no contexto do trabalho; avaliação que faz de si mesmo (antes e depois da inserção no trabalho); como utilizou o salário; recomendações que faria a outros adolescentes que começassem a mesma atividade; perguntas que faria a outro adolescente se fosse o entrevistador. Visava-se abertura às contribuições do entrevistado e à sua forma de orientação no mundo.

Metade dos adolescentes selecionados trabalhava em instituições públicas e a outra metade, em empresas privadas. Procurou-se realizar a entrevista em local que melhor se adequava à disponibilidade do adolescente, mantendo a ressalva de não realizá-la em seu local de trabalho.

As entrevistas foram gravadas, transcritas e passaram por procedimentos de análise de conteúdo, segundo definida por Bardin (1977) e Bauer (2002). Quanto ao processo de gravação, utilizou-se um gravador de fita cassete portátil que era acionado manualmente após autorização formal escrita do adolescente para realização da entrevista. O tempo de gravação de cada fita era de 60 minutos, de forma que na maioria dos casos cada entrevista pôde ser gravada numa única fita, numerada conforme a sequência de realização. Para a transcrição, as fitas eram reproduzidas com o próprio gravador através de fones de ouvido, de forma que podiam ser ditadas pelo pesquisador para um computador através do software ViaVoice for Windows 8.0. Os textos resultantes foram submetidos ao editor de texto Microsoft Office Word 2003 , e versões compatíveis. As entrevistas eram identificadas com a sequência de sua realização, o local em que foram realizadas, data e hora do início da coleta. Transcreveram-se fielmente as falas dos adolescentes e do pesquisador, inclusive com expressões coloquiais, reformulações de frases e repetições de fonemas, de forma que permitissem servir também de pistas adicionais para a definição das categorias. Os trechos mais importantes foram destacados com marcador de texto no próprio editor. Foram criados documentos de texto intermediários com recortes de falas dos adolescentes a fim de definir categorias. Cada trecho de fala destacado pôde ser reduzido a uma unidade de significado, o que permitiu a quantificação os dados. Quanto ao processo de análise propriamente dito, as categorias predefinidas foram utilizadas como critérios para reprocessamento dos dados coletados. Voltou-se às transcrições a fim de reavaliar os trechos de fala segundo as unidades de significado definidas pelas categorias. Isso permitiu refinar o crivo de análise e criar subcategorias. As entrevistas dos adolescentes não foram comparadas entre si de forma individualizada. Os dados foram tabelados segundo categorias e subcategorias, os resultados dentro de uma mesma categoria foram somados e utilizou-se porcentagem simples para quantificar o aparecimento de unidades de significado de acordo com as subcategorias.

\section{Resultados}

Os dados das entrevistas foram classificados segundo categorias de análise numeradas de (1) a (9). As categorias foram depreendidas dos próprios relatos e perguntas/estímulos. Seguem a definição de cada categoria e um exemplo de fala nela enquadrada.

Demanda familiar (1). Refere-se ao fato da renda do adolescente poder ser a principal da família, complementar ou desembaraçada dos gastos essenciais para sobrevivência. 
Exemplo: "quando eu comecei a trabalhar eu ajudava em casa, pegava todo o meu salário e dava em casa. $\mathrm{O}$ meu ticket alimentação, que lá tem, ficava tudo em casa. 'ohh, mãe, isso aqui você pega e faz compra'” (Entrevista 04).

Trabalho pregresso (2). Trata das experiências de trabalho do adolescente antes de ser inserido formalmente no mercado de trabalho através da instituição a qual se vinculava. Exemplo:

Era época que a gente trabalhava, assim, debaixo de chuva, sem camisa, e... mal vestido, descalço, com aquelas butina rasgada... (...) eu sempre falo que eu trabalhava que nem cavalo, porque, ali você pegava muito peso e não podia parar... trabalhava muito, puxado às vezes e não... era um trabalho assim que não era reconhecido por ninguém (...) entregar essa compra tarde, dez horas da noite, (...) e o pessoal tratava a gente na maior ignorância, queria tacar o negócio na gente, queria humilhar, queria desfazer da gente. Aí eu, aí eu via, que aquilo dali não era pra mim" (Entrevista 04).

Acesso a lazer (3). Reúne falas nas quais o adolescente comenta experiências relacionadas a divertimento e acesso a bem culturais não restritos a trabalho ou estudos.

Eu queria comprar um baixo, aí eu não tinha condições de comprar, agora eu posso comprar, no mês que vem estou comprando já que... eu vou tocar baixo na banda... prá mim poder... têm todos os instrumentistas, só falta o baixista, que sou eu... Aí quando nós... vamos montando... tão montando já, a banda já... a banda tá crescendo, nós estamo tocando direto, fazendo show...(Entrevista 07$)$

Vida escolar (4). Refere-se aos comentários sobre as atividades relacionadas a rotinas escolares.

É... e você também quando trabalha muito, (...) igual tô no estágio de oito horas e... estuda a noite, você não consegue fazer nada de dia... trabalhos, vamos dizer, escolar, assim. (...). Isso que muda. Pesa um pouquinho, você... as minhas notas que eu tinha antes, vamos dizer, eu não tenho agora por causa... dessa consequência aí... dessa... desses afazeres. (Entrevista 13)

Projeto de vida (5). Diz respeito aos planos do adolescente para o período imediatamente posterior ao encerramento do seu contrato de trabalho.

O que realmente eu tenho como projeto é seguir essa minha carreira em Ciências Biológicas, assim, numa universidade mesmo que trabalha mais com pesquisa (...) as minhas pretensões acadêmicas continuaram as mesmas, quando eu mudei para uma empresa que era de caráter público eu já vi que ali não era nada do que eu queria, o que eu quero, ainda, é continuar esse lado mais da Ciência. (Entrevista 09)

Empregabilidade (6). Define as estratégias que supostamente ajudaria os adolescentes a: aumentar sua chance de serem efetivados, após o término do contrato, na empresa em que trabalhavam; ser admitidos em outras empresas para serviços semelhantes aos desenvolvidos; manter-se com capacidade de admissão no mercado de trabalho formal, ainda que esse não fosse o objetivo imediato. Exemplo:
Já vou ter uma ideia do que é mercado de trabalho, né. Pra saber mais ou menos o quê que eu vou fazer... o que eu posso tentar na universidade, o que eu posso tentar fazer... E também, o contrato acabou, aí alguém pode me indicar pra trabalhar em certo lugar. Porque hoje em dia também, eles contam muito com isso, com a indicação, das pessoas que estão saindo das empresas. (Entrevista 02)

Exploração do trabalho (7). Define comentários referentes a uma suposta extrapolação da carga de trabalho previamente definida em contrato e/ou alguma forma de desqualificação do mesmo no contexto da inserção formal.

Foi um ano e noves meses bom, me trataram com respeito... nunca exploraram também... Ficava depois do horário, mas não porque assim eles pediam, por que como eu atendia o telefone, a pessoa que pegava... chegava depois de mim ela se atrasava, aí eu não podia sair, deixar o telefone sozinho, aí eu ficava lá, aí a chefe conversava comigo, no dia que eu quisesse sair cedo ela podia me liberar. E isso eu não posso dizer que é exploração porque isso daí foi da minha parte mesmo, ela perguntou se eu podia ficar, eu respondi que poderia. (Entrevista 05 )

Discriminação social (8). Refere-se a condutas de colegas de trabalho, percebidas pelos adolescentes, que tivessem como resultado os desabonar como pessoa em função de cor, sexo, etnia, religião, classe social, espaço de moradia, dentre outras.

Acho que era a aparência que eu tinha... uma cara de... de quem não prestava, entendeu... apesar de que eu nunca fui isso... sempre fui uma pessoa certa. (...) logo que eu comecei, as pessoas de lá não confiavam em mim... eles achavam que eu era um... uma pessoa de... uma pessoa... que não podia se confiar, entendeu. Eles não mandavam fazer quase nada, (...) até que com o passar do tempo (...) foi confiando, é... passou... (...) confia mais em mim do que em alg... próprios funcionários que trabalham junto (...). Deixa cartão na minha mão, deixa senha de cartão comigo, (...) eu tenho muita confiança, (...) todos ali têm. (Entrevista 06)

Uso do salário (9). Caracteriza um detalhamento mais preciso do tipo de bens ou serviços que o adolescente acessou ao gastar seu dinheiro ou ticket que recebia, independentemente de beneficiar a si mesmo ou sua família. Exemplo:

Com certeza, porque agora eu... estou passando a comprar minhas coisa, né, é... comprei minha televisão, meu guardaroupa, minha cama... e tou pagando, né. E assim, o dinheiro do mês, né, vai totalmente... praticamente para pagar, né. E eu não posso fazer dívida nenhuma. (Entrevista 14)

Essas categorias foram subdivididas em subcategorias, também depreendidas dos próprios relatos e perguntas/estímulos. Passa-se a rever cada categoria segundo suas subcategorias.

Quanto à Demanda familiar (1) de apoio financeiro, a fonte de renda dos adolescentes foi considerada a principal da família em 6,67\% dos casos, livre para utilização pessoal desembaraçada dos gastos essenciais da família em 13,33\% e complementar à renda familiar em $80 \%$ dos relatos. Para a maioria dos adolescentes, o acesso ao trabalho não se configurava como um direito, mas como um dever decorrente de sua necessidade de 
sobrevivência. Corrobora esse dado o fato de que apenas 26,67\% deles não tiveram experiência de Trabalho pregresso (2), contra $20 \%$ que fizeram avaliação positiva da mesma e 53,33\% que fizeram avaliação negativa daquela experiência. Nota-se que a partir de sua experiência de trabalho formal, puderam refletir sobre o nível de desqualificação, falta de reconhecimento e desvalorização a que estavam submetidos em suas experiências pregressas de trabalho informal.

A inserção profissional assistida possibilitou investir mais no acesso a Lazer (3). Assim, 40\% perceberam melhora nas atividades de lazer, passando a frequentar shows, cinema, fazer lanche no shopping, além de comprar roupas mais adequadas ao perfil jovem desses ambientes. 33,33\% avaliaram que o lazer piorou, alegando redução do tempo livre entre trabalho e estudo, o que não reflete necessariamente a qualidade das atividades de lazer, mas o aumento de compromissos, considerando que parte deles desempenhava papéis ativos em suas comunidades religiosas. Nota-se que, no teor dos relatos, o lazer não se configura como um direito por si mesmo, mas como uma espécie de licença devido ao fato de estar trabalhando. $26,67 \%$ deles não comentaram esse aspecto de sua inserção.

Considerando a Vida escolar (4), 46,67\% melhoraram seu desempenho escolar com notas e execução das atividades. Colaboraram para essa avaliação a formação disponibilizada nos cursos introdutórios, as recomendações no ambiente de trabalho, o acesso a recursos para desempenho de atividades escolares, bem como novas motivações decorrentes do projeto de vida. Dos entrevistados, 13,33\% dizem que esse aspecto não mudou, $20 \%$ não comentaram seu desempenho escolar, e outros $20 \%$ referem piora nos estudos, ora pela redução do tempo livre, considerando que alguns chegaram a trabalhar 8 horas diárias antes da incidência de nova legislação reguladora da carga horária de trabalho adolescente, ora porque avaliaram a escola frequentada como não correspondendo em qualidade àquilo que passaram a aspirar academicamente. Sarriera et al. (2001) destacam que “o trabalho poderá ser estruturante da identidade se puder proporcionar ao jovem um sentido de vida, facilitando suas escolhas profissionais à medida que possa ser fonte de informações e aprendizagem" (p. 28).

Em relação ao trabalho exercido, $60 \%$ enunciaram como Projeto de vida (5) a expectativa de (a) efetivar-se no emprego, $73,33 \%$ tinha planos de cursar uma (b) faculdade relacionada às atividades exercidas e $40 \%$ desejavam uma (c) faculdade não relacionada. Não sendo mutuamente excludentes, tais escolhas variaram em função das possibilidades de acesso ao ensino público ou particular, via projetos governamentais ou financiamentos, que muitas vezes dependem de um vínculo de trabalho para serem mantidos. Assim, combinando os enunciados, pudemos analisar que $6,67 \%$ dos adolescentes tinham exclusivamente a expectativa de efetivar-se no emprego, 20\% tinham planos de cursar faculdade relacionada ao trabalho e 13,33\% tinham planos de cursar faculdade não relacionada ao emprego. Expressão considerável teve as expectativas combinadas $(\mathrm{a}+\mathrm{b}), \operatorname{com} 33,33 \%$ das entrevistas, implicando que o trabalho exercido teve forte impacto na reorientação de seus projetos. Alguns adolescentes comentaram ter vivenciado situações simplesmente jamais imaginadas por eles fora do contexto de uma experiência de trabalho formal protegido institucionalmente. Ficaram nas expectativas $(\mathrm{a}+\mathrm{c})$ 6,67\% dos entrevistados, devido terem projetos anteriores que se mantiveram inalterados. Importante perceber que $20 \%$ mantiveram expectativas conflitantes, sendo que $6,67 \%$ enunciaram projetos do tipo $(b+c)$ e $13,33 \%$ projetos $(a+b+c)$, o que pode refletir necessidade de intervenções psicossociais no estilo orientação vocacional e/ou profissional, ou outro tipo de suporte nas fases finais do processo de inserção laboral assistida. Ainda que a mesma facilite o processo de elaboração do projeto de vida e garanta acesso a direitos sociais básicos, há uma dimensão afetiva que não pode ser corretamente avaliada exceto que se considerem aspectos da subjetividade desse adolescente e seus múltiplos determinantes sociais, que não se referem apenas à condição de sub-cidadania.

Fazer um curso superior também caracterizava preocupação em manter a Empregabilidade (6), sendo que 40\% referiram uso instrumental de (A) Amizades e Redes Sociais como forma de tentar manter-se no emprego após o encerramento do contrato. $80 \%$ recorreram a (B) Habilidades Técnicas como cursos profissionalizantes, informática, línguas, técnicas administrativas, dentre outras. $60 \%$ investiram em outras habilidades comportamentais, como mudança de hábitos culturais, forma de falar, hábito de leitura, relações humanas, dentre outras categorizadas genericamente como (C) Habilidades Subjetivas. Quando feita uma análise das estratégias de Empregabilidade combinadas, 20\% investiram em $(\mathrm{A}+\mathrm{B}+\mathrm{C}), 33,33 \% \mathrm{em}(\mathrm{B}+\mathrm{C}) \mathrm{e}$ $20 \%$ em (A+B). Esse tipo de valorização pode ser explicado pelas ênfases formativas dos períodos iniciais da inserção assistida. Por outro lado, 13,33\% sinalizaram não seguir nenhuma, $6,67 \%$ exclusivamente (B) e outros $6,67 \%$ apenas (C). Verifica-se que, apesar da adoção exclusiva da estratégia (A) fosse possível, isso não ocorreu. Parece contraditório, considerando que os adolescentes enfatizaram a importância de fazer amizades no ambiente de trabalho. Contudo, isso se explica pelo fato de que alguns adolescentes perceberam que a existência de conflitos interpessoais nas relações de trabalho chegava a determinar negativamente promoções ou demissões, passando a recorrer à estratégia (A) apenas defensivamente, o que caracterizou tolerância a algumas situações de exploração.

Percebe-se a importância do sentido social do trabalho ao "permitir novos contatos sociais, ampliando a rede de amizades e a social" (Sarriera et al., 2001, p. 28). Contudo, essa mesma rede social também pode atuar como um filtro que desmotiva a busca de amparo, sob argumentos afetivos potencialmente clientelistas como o da manutenção da amizade, mesmo que o apoio institucional esteja efetivamente à disposição.

Apenas alguns adolescentes mencionaram situações de Exploração do Trabalho (7), sendo que 46,67\% não comentaram e 26,67\% explicitaram não sofrer. $13,33 \%$ Percebem os colegas sendo explorados e 26,67\% sofreram exploração. Apesar da valorização positiva do trabalho formal, relatou-se o exercício de diversas atividades não qualificadas, relacionadas à manutenção dos serviços prestados no mercado pelas empresas em que trabalhavam. Um adolescente chegou a usar a expressão descarrego de funções, que diferenciava negativamente o trabalho do estagiário relativamente ao do funcionário da empresa. 
Foram mencionadas situações de desqualificação de seu modo de vida, como a promoção de valores que os afastam de seus iguais. Contudo, no que se refere à Discriminação Social (8), $53,33 \%$ não comentaram, $13,33 \%$ disseram explicitamente que não sofreu, 13,33\% perceberam os colegas sofrendo e 13,33\% referiram que sofreu. Curiosamente, um adolescente procurou um curso de português instrumental a fim de melhorar sua habilidade com a língua portuguesa para tratar melhor com as "pessoas sociais" (sic). O ambiente de trabalho formal os colocou em contato com pessoas de nível cultural elitizado em relação ao seu padrão. Isso pode sinalizar necessidade de treinamento em habilidades sociais assertivas, pois a busca de identificação com colegas de trabalho parece implicar tanto a desqualificação de sua forma de se colocar no mundo, de se expressar, que também é legítima, quanto seu afastamento do grupo de pares.

Finalmente, quanto ao Uso do Salário (9), todos o utilizaram ao menos parcialmente para consumo próprio, como roupas, material de manutenção das atividades escolares, lazer, etc., $40 \%$ contribuíram com gastos familiares em alimentação, geralmente quando percebiam tickets como complemento do salário. Cerca de 60\% ajudavam com contas de água, luz, etc. Quanto à Moradia, 6,67\% contribuía com aluguel e 13,33\% com construção. Esses dados detalham aqueles referentes à Demanda Familiar (1).

\section{Discussão}

Os dados referentes à Demanda Familiar (1) e Uso do Salário (9) mostram que a principal motivação dos adolescentes para seu ingresso no mercado de trabalho, ainda que formal e institucionalmente assistido, continua sendo seu papel estratégico de coadjuvante na sobrevivência familiar, como observam Costa (1990), Minayo-Gomez e Meirelles (1997), Oliveira e Robazzi (2001) e Fischer et al. (2003).

Apesar de haver indícios de flexibilização das relações de trabalho em alguns casos, acenando para uma desqualificação em função do baixo nível escolar dos adolescentes, tal como observa Ferreira (2001), a experiência de trabalho neste caso possibilitou aos adolescentes melhorar a qualidade de sua relação com a escola de forma a compor um projeto de vida orientado para busca de melhores oportunidades de colocação no mercado de trabalho, inclusive via acesso à universidade. Neste sentido, os dados relativos ao Projeto de Vida (5) demonstram que o trabalho possibilitou situações de empoderamento tal como definidas por Iulianelli (2003), considerando que, mesmo sob intenso estímulo institucional, os adolescentes tiveram relativa liberdade ao definir suas aspirações a partir de projetos pessoais que entendiam não serem passíveis de realização antes da inserção laboral assistida.

Quanto à Empregabilidade (6), esta não se configurou apenas como mecanismo defensivo dos trabalhadores adolescentes como sugerem as observações de Estêvão (2001) quanto à culpabilização do trabalhador por sua situação laboral. Isso ocorreu, apesar de estarem sensíveis e buscarem ativamente a composição de um currículo de habilidades, às vezes mais ou menos oculto, tal como sugerem Shiroma \& Campos (1997). Corroborando Piccinini (2004), a maioria dos entrevistados pensa em investir na aprendizagem de técnicas ou tecnologias, sinalizando que a condição de sua empregabilidade poderia estar orientada para evitar o subemprego definido por eventuais investimentos tecnológicos em redução de mão de obra. A referência de Sorj (2000) quanto à possibilidade de uso de características pessoais como condição de empregabilidade não pode ser verificada, tendo em vista que a supervisão institucional tendeu a reduzir conflitos referentes a situações de Discriminação Social (8), apesar de ainda ocorrerem em algumas situações e se perceber relativa reticência dos adolescentes em comentar situações compatíveis com esse fator.

No que tange à categoria Exploração do Trabalho (7) houve a percepção por considerável parte dos adolescentes de situações de extrapolação da carga de trabalho, acúmulo de funções ou exercícios de funções não previamente combinadas. Observa-se que a conversão do adolescente em trabalhador subserviente pode acontecer exatamente por via das relações de poder aí existentes. Segundo Foucault (1987), o poder não está limitado a aspectos institucionais e/ou organizacionais, mas está presente mesmo em relações de amizade, como confirmam Zanella, Prado Filho e Abella (2003) ao se referir às redes sociais. Somada à preocupação com sua empregabilidade, isso não deixa de constituir um mecanismo difuso de poder de que se serve o capitalismo neoliberal, com suas consequências para a desqualificação da força de trabalho e o estímulo a um protagonismo no qual o trabalhador se forme a si mesmo consumindo uma educação tornada mercadoria.

\section{Conclusões}

A inserção laboral assistida pode reduzir o impacto da exploração do trabalho adolescente em condições de subcidadania. Contudo, isso provavelmente ocorre num contexto apenas reparador dessa condição, não conseguindo efetivamente representar um nível de ação mais preventiva, como mostraram os dados referentes a trabalho pregresso dos adolescentes.

Dessa forma, observa-se que a inserção assistida no mercado de trabalho formal não constitui garantia absoluta de proteção dos direitos dos adolescentes, especialmente pelo fato de que as redes sociais às quais os adolescentes se vinculam no ambiente de trabalho podem ocultar algumas violações de direitos, às vezes, compatíveis com relações de clientelismo. Há que se considerar, também, a possibilidade da assimilação de valores sociais do contexto do ambiente laboral implicar relativo afastamento do grupo de pares.

Concordamos com a ideia de que "acolhimento, proteção e compreensão seriam os marcos desejáveis da ação institucional nas áreas de educação, assistência social e justiça" (Ferreira, 2001, p. 223). Tanto que todos os adolescentes avaliaram positivamente o acompanhamento fornecido pela instituição. Mas que, "no entanto, há muito conhecimento a produzir para adequar medidas que sejam libertadoras, promotoras da condição de cidadania, propulsoras da autonomia social aos milhares de microespaços do país" (p. 223).

Do ponto de vista político, os efeitos disso para o exercício da democracia, da conquista da cidadania, são de importância crucial, já que é no fazer dos sujeitos que se dá essa construção, possibilitada pelas relações sociais. Do ponto de vista prático, 
as instituições devem reforçar esse duplo investimento: no preparo objetivo possibilitado pelo ensino de habilidades técnicas específicas (cursos de informática, por exemplo); e subjetivo, reforçando a habilidade de interferir positivamente no desenrolar das relações sociais nas quais os adolescentes se envolvem, possibilitando questionamento do modelo de democracia que as instituições e o Estado veiculam, já que é produto de múltiplos compromissos que nem sempre levam em conta os interesses dos sujeitos aos quais se dirigem.

\section{Agradecimentos}

O autor agradece as contribuições da orientadora do trabalho de mestrado que originou essa publicação, a professora $\operatorname{Dr}^{\mathrm{a}}$ Helerina Aparecida Novo.

\section{Referências}

Ariès, P. (1981). História social da criança e da família. Rio de Janeiro: Guanabara.

Bardin, L. (1977). Análise de conteúdo. Rio de Janeiro: Edições 70.

Bauer, M. W. (2002). Análise de conteúdo clássica: uma revisão. In M. W. Bauer \& G. Gaskell (Orgs.). Pesquisa qualitativa com texto, imagem e som: um manual prático (pp. 189-217). Petrópolis: Vozes.

Bauman, Z. (1999). Globalização: as conseqüencias humanas (M. Penchel, Trad.). Rio de Janeiro: Jorge Zahar.

Campos, H. R., \& Francischini, R. (2003). Trabalho infantil produtivo e desenvolvimento humano. Psicologia em Estudo, 8(1), 119-129.

Coimbra, C. M. B., \& Nascimento, M. L. (2003). Jovens pobres: o mito da periculosidade. In P. C. P. Fraga, \& J. A. S. Iulianelli, (Orgs.), Jovens em tempo real (pp. 19-37). Rio de Janeiro: DP\&A.

Costa, A. C. G. (1990). Infância, juventude e política social no Brasil. In A. C. G. Costa, A. F. A. Silva, D. Rivera, E. S. Moraes, \& M. Cury (Orgs.), BRASILCriança-Urgente: A Lei 8.069/90 (vol. 3, pp. 69-105). São Paulo: Columbus.

Diniz, E. (2000). A busca de um novo modelo econômico: padrões alternativos de articulação público-privado. Revista de Sociologia e Política, 14, 7-28.

Enguita, M. F. (1989). A face oculta da escola: educação e trabalho no capitalismo (T. T. Silva, Trad.). Porto Alegre: Artes Médicas.

Estêvão, C. V. (2001). Formação, gestão, trabalho e cidadania: contributos para uma sociologia crítica da formação. Educação \& Sociedade, 22(77), 185-206.

Ferreira, M. A. F. (2001). Trabalho infantil e produção acadêmica nos anos 90: tópicos para reflexão. Estudos de Psicologia (Natal), 6(2), 213-225.

Fischer, F. M., Oliveira, D. C., Teixeira, L. R., Teixeira, M. C. T. V., \& Amaral, M. A. (2003). Efeitos do trabalho sobre a saúde de adolescentes. Ciência \& Saúde Coletiva, 8(4), 973-984.

Foucault, M. (1987). Vigiar e punir: o nascimento da prisão. Petrópolis: Vozes.
Foucault, M. (2000). Em defesa da sociedade. Curso no Collége de France (19751976) (M. E. Galvão, Trad.). São Paulo: Martins Fontes.

Iulianelli, J. A. S. (2003). Juventude: construindo processos - o protagonismo juvenil. In P. C. P. Fraga \& J. A. S. Iulianelli (Orgs.), Jovens em tempo real (pp. 54-75). Rio de Janeiro: DP\&A Editora.

Lei $n^{\circ}$ 8.069, de 13 de julho de 1990. (1990, 13 de julho). Dispõe sobre o Estatuto da Criança e do Adolescente e dá outras providências. Recuperado de http:// www.planalto.gov.br/ccivil 03/leis/L8069Compilado.htm

Magalhães, R. (2002). Enfrentando a pobreza, reconstruindo vínculos sociais: as lições da ação da cidadania contra a fome, a miséria e pela vida. Cadernos de Saúde Pública, 18, 121-137.

Maricato, E. (2000). Urbanismo na periferia do mundo globalizado: metrópoles brasileiras. São Paulo em Perspectiva, 14(4), 21-33.

Mendonça, M. H. M. (2002). O desafio da política de atendimento à infância e à adolescência na construção de políticas públicas eqüitativas. Cadernos de Saúde Pública, 18, 113-120.

Minayo-Gomez, C., \& Meirelles, Z. V. (1997). Crianças e adolescentes trabalhadores: um compromisso para a saúde coletiva. Cadernos de Saúde Pública, 13(Supl. 2), 135-140.

Oliveira, B. R. G., \& Robazzi, M. L. C. C. (2001). O trabalho na vida dos adolescentes: alguns fatores determinantes para o trabalho precoce. Revista Latino-Americana de Enfermagem, 9(3), 83-89.

Oliveira, D. C., Sá, C. P., Fischer, F. M., Martins, I. S., \& Teixeira, L. R. (2001) Futuro e liberdade: o trabalho e a instituição escolar nas representações sociais de adolescentes. Estudos de Psicologia (Natal), 6(2), 245-258.

Oliveira, D. C., Fischer, F. M., Amaral, M. A., Teixeira, M. C. T. V., \& Sá, C. P. (2005). A positividade e a negatividade do trabalho nas representações sociais de adolescentes. Psicologia: Reflexão e Crítica, 18(1), 125-133.

Piccinini, V. C. (2004). Cooperativas de trabalho de Porto Alegre e flexibilização do trabalho. Sociologias, 12, 68-105.

Ramos, F. P. (2002). Inserção Laboral: Impactos na Identidade e nas Relações Sociais de Adolescentes Carentes (Dissertação de Mestrado não publicada). Universidade Federal do Espírito Santo, Vitória.

Rossi, V. L. S. (2001). Desafio à escola pública: tomar em suas mãos seu próprio destino. Cadernos CEDES, 21(55), 92-107.

Sarmento, M. J. (2002). Infância, exclusão social e educação como utopia realizável. Educação \& Sociedade, 23(78), 265-283.

Sarriera, J. C., Silva, M. A., Kabbas, C. P., \& Lopes, V. B. (2001). Formação da identidade ocupacional em adolescentes. Estudos de Psicologia (Natal), $6(1), 27-32$.

Shiroma, E. O., \& Campos, R. F. (1997). Qualificação e reestruturação produtiva: um balanço das pesquisas em educação. Educação e Sociedade, 18(61), 13-35.

Sorj, B. (2000). Sociologia e trabalho: mutações, encontros e desencontros. Revista Brasileira de Ciências Sociais, 15(43), 25-34.

Zanella, A. V., Prado Filho, K., \& Abella, S. I. S. (2003). Relações sociais e poder em um contexto grupal: reflexões a partir de uma atividade específica. Estudos de Psicologia (Natal), 8(1), 85-9 
Victor Hugo da Silva, mestre em Psicologia pela Universidade Federal do Espírito Santo (Bolsista CAPES), é psicólogo da Prefeitura Municipal de Colatina-ES. Endereço para correspondência: Rua Pedro Epichim, 1973, Bairro IBC, Colatina/ES. CEP: 29.700-550. Tel.: (27) 8124-8900. E-mail: victorunico@hotmail.com 